\title{
Stage III Adrenal Gland Pheochromocytoma and Sympathetic Paraganglioma AJCC v8
}

National Cancer Institute

\section{Source}

National Cancer Institute. Stage III Adrenal Gland Pheochromocytoma and Sympathetic Paraganglioma A/CC V8. NCI Thesaurus. Code C141131.

Stage III includes: (T1, N1, M0); (T2, N1, M0); (T3, Any N, M0). T1: Pheochromocytoma measuring less than $5 \mathrm{~cm}$ in greatest dimension, with no extra-adrenal invasion. T2: Pheochromocytoma measuring $5 \mathrm{~cm}$ or more in greatest dimension or parag ang liomasympathetic of any size, with no extra-adrenal invasion. T3: Tumor of any size with invasion into surrounding tissues (e.g., liver, pancreas, spleen, kidneys). N1: Regional lymph node metastasis. M0: No distant metastasis. (from AJCC 8th Ed.) 